\title{
In vivo Kinematics of the Knee after a Posterior Cruciate-Substituting Total Knee Arthroplasty: A Comparison between Caucasian and South Korean Patients
}

\author{
Ji-Hoon Bae, $\mathrm{MD}^{1,2}$, Ali Hosseini, $\mathrm{PhD}^{1}$, Kyung-Wook Nha, $\mathrm{MD}^{3}$, Sang-Eun Park, $\mathrm{MD}^{4}$, Tsung Yuan Tsai, $\mathrm{PhD}^{1}$, \\ Young-Min Kwon, $\mathrm{MD}^{1}$, and Guoan $\mathrm{Li}, \mathrm{PhD}^{1}$ \\ ${ }^{1}$ Bioengineering Laboratory, Department of Orthopaedic Surgery, Massachusetts General Hospital/Harvard Medical School, Boston, MA, USA; ${ }^{2}$ Department of \\ Orthopaedic Surgery, Korea University Guro Hospital, Seoul, Korea; ${ }^{3}$ Department of Orthopaedic Surgery, Inje University Ilsan Paik Hospital, Goyang, Korea; \\ ${ }^{4}$ Department of Orthopaedic Surgery, Dongguk University Ilsan Hospital, Goyang, Korea
}

\begin{abstract}
Purpose: This study compared in vivo kinematic differences between Caucasian and South Korean patients after a posterior-substituting total knee arthroplasty (PS-TKA).

Materials and Methods: In vivo motions of 9 Caucasian and 13 South Korean knees with a PS-TKA during weight bearing single leg lunge were determined using a dual fluoroscopic imaging technique. Normalized tibiofemoral condylar motions and articular contact locations were analyzed. Results: Femoral condylar motions of the two groups showed a similar trend in anteroposterior translation, but the South Korean patients were more anteriorly positioned than the Caucasian patients at low flexion and maximal flexion angles in both medial and lateral compartments ( $\mathrm{p}<0.05$ ). Mediolateral femoral condyle translations were similar between the two groups. For tibiofemoral articular contact kinematics, the South Korean patients had significantly more anterior contact locations at the medial compartment at low flexion angles, and more lateral contact locations at the lateral compartment at $0^{\circ}$ and $90^{\circ}$ flexion compared to the Caucasian patients $(\mathrm{p}<0.05)$. The South Korean patients had significantly larger distances between the medial and lateral contact locations at $60^{\circ}$ and $90^{\circ}$ flexion compared to the Caucasian patients $(\mathrm{p}<0.05)$.

Conclusions: The study revealed that while the Caucasian and South Korean knees had similar femoral condylar motions, after PS-TKA the South Korean patients showed different articular contact point kinematics compared to the Caucasian patients.
\end{abstract}

Keywords: Knee, Kinematics, Caucasian, Asian, Arthroplasty

Received September 23, 2015; Revised December 19, 2015;

Accepted January 5, 2016

Correspondence to: Guoan $\mathrm{Li}, \mathrm{PhD}$

Bioengineering Laboratory, Department of Orthopaedic Surgery,

Massachusetts General Hospital/ Harvard Medical School, 55 Fruit

Street, GRJ 1215, Boston, MA 02114, USA

Tel: +1-617-724-3246, Fax: +1-617-724-4392

E-mail: Li.Guoan@mgh.harvard.edu

This is an Open Access article distributed under the terms of the Creative Commons Attribution Non-Commercial License (http://creativecommons.org/licenses/by-nc/4.0/) which permits unrestricted non-commercial use, distribution, and reproduction in any medium, provided the original work is properly cited.

\section{Introduction}

There is a rapid increase of total knee arthroplasty (TKA) in Asian countries ${ }^{1,2}$. Recent studies reported that Asian patients after TKA are less likely to be satisfied with their knees compared to Caucasian patients, although clinical outcomes were improved $^{3,4}$. However, most TKA implants currently used in Asian patients were developed in Western countries. These components were usually designed to target on Caucasian knees and Western life styles. Biomechanical studies have revealed morphological distinctions between Caucasian and Asian knees ${ }^{5,6)}$. Asian knees were shown to have smaller size with different mediolateral (ML) to anteroposterior (AP) ratio (ML/AP) of distal femur and 
proximal tibia compared to Caucasian knees. A size mismatch of the femoral or tibial implants relative to the host bone has been widely assumed to affect soft tissue function and result in altered knee kinematics.

Besides the anatomic differences ${ }^{5-10}$, kinematic variations were also reported between the Caucasian and Asian knees ${ }^{11)}$. Leszko et al. ${ }^{11)}$ reported differences in knee kinematics and range of motion (ROM) between a Caucasian and a Japanese population, especially between the Caucasian men and Japanese women. While this study provided insights into the understanding of ethnic differences in normal knee kinematics, it is unclear of the differences in knee kinematics after TKA between Caucasian and Asian patients. This information is important for investigation of the functionality and longevity of the components when implanted in Asian patients.

Therefore, the objective of this study was to examine whether there are kinematic differences between Caucasian and Asian patients after TKA using the same component design. Specifically, the femoral condyle motion and articular contact kinematics of the knee during a weight bearing single leg lunge were investigated using a dual fluoroscopic imaging system ${ }^{12,13)}$. Based on the different morphologic characteristics of the knee between the Caucasian and Asian people $\mathrm{e}^{7,14)}$, we hypothesized that there are distinct differences in tibiofemoral kinematics between the Caucasian and Asian patients after TKA.

\section{Materials and Methods}

\section{Subjects}

Nine living Caucasian knees (range, 66 to 78 years) and 13 South Korean knees (range, 61 to 74 years) were studied with Institutional Review Board approval ${ }^{15-18)}$ (Table 1). All knees were operated using a fixed bearing posterior-substituting (PS) TKA (Nexgen LPS-Flex; Zimmer, Warsaw, IN, USA) and were evaluated as clinically successful at the time of postoperative follow-up.

\section{Surgical Techniques}

Both Caucasian and South Korean knees were operated using similar techniques ${ }^{16)}$. A midline incision was made, which was followed by a medial parapatellar arthrotomy. The distal femur was cut in $5^{\circ}$ of valgus using an intramedullary alignment guide. The transepicondylar axis was used to assess rotational alignment of the femoral implant with the posterior femoral condyles and Whiteside's line used as additional references. Tibial alignment was performed using an extramedullary guide, and the tibia was cut with a $5^{\circ}$ posterior slope. Prior to cementing the definitive components, a trial reduction was performed with careful attention to the assessment of the flexion and extension gaps, stability, ROM, and patellar tracking. The patella was resurfaced in all patients. The extensor mechanism and skin were closed with sutures in a standard fashion.

\section{In vivo Experimental Design}

All patients were tested one year after TKA. Each patient performed a single leg, weight bearing lunge from full extension to maximal flexion using the operated knee. The patient was instructed to bend the knee slowly and hold the knee position at each $15^{\circ}$ increment of flexion for about 2 seconds while knee images were captured using the dual fluoroscopic imaging system $(\mathrm{DFIS})^{12,13)}$. The positions of the two fluoroscopes were then recreated in a solid modeling software (Rhinoceros; Robert McNeel \& Associates, Seattle, WA, USA) to construct a virtual DFIS ${ }^{12,19)}$. The paired images captured at each flexion angle were used to create two virtual image intensifiers. Three-dimensional (3D) computer-aided design models of the TKA components (femoral \& tibial components and polyethylene tibial insert) were imported into the virtual dual fluoroscopic system. The component models were manipulated in space and projected onto the virtual image intensifiers until their projections matched the outlines of the components on the fluoroscopic images. Therefore, the TKA component positions along the single leg lunge path were reproduced using a series of 3D TKA models.

Table 1. Subject Demographics

\begin{tabular}{lccc}
\hline \multicolumn{1}{c}{ Characteristic } & South Korean & Caucasian & p-value \\
\hline Gender $(\mathrm{M} / \mathrm{F})$ & $0 / 13$ & $7 / 2$ & \\
Age $(\mathrm{yr})$, mean (range) & $61-74$ & $66-78$ & $\mathrm{NS}$ \\
BMI $\left(\mathrm{kg} / \mathrm{m}^{2}\right)$, mean (range) & $23.2-30.1$ & $25.1-32.5$ & $\mathrm{NS}$ \\
Passive ROM $\left(^{\circ}\right)$, mean \pm SD & $142.5 \pm 9.2$ & $118.6 \pm 14.0$ & 0.003 \\
Weight bearing ROM $\left(^{\circ}\right)$, & $117.5 \pm 15.1$ & $117.4 \pm 23.9$ & NS \\
mean \pm SD & & & \\
Femoral component & Size 4 (2) & Size 5 (2) & \\
(no. of knees) & Size 5 (11) & Size 6 (5) & \\
& & Size 7 (2) & \\
Tibial component & Size 3 (8) & Size 3 (1) & \\
(no. of knees) & Size 4 (4) & Size 5 (4) & \\
& Size 5 (1) & Size 6 (1) & \\
& & Size 7 (2) & \\
& & Size 8 (1) & \\
\hline
\end{tabular}

SD: standard deviation, NS: not significant ( $p>0.05)$, BMI: body mass index, ROM: range of motion. 


\section{Femoral Condylar Motion and Tibiofemoral Contact} Location

The femoral condylar motions and articular contact areas were determined using the series of matched TKA components. To calculate femoral condyle motion, local coordinate systems were created for both the tibial and femoral components (Fig. 1) ${ }^{12)}$. The flexion axis of the femoral component was defined as the line connecting the tips of the two pegs of the component (Fig. 1A). Motion of the femoral component was defined as the positions of the tips of the pegs in tibial coordinate system. The axial rotation

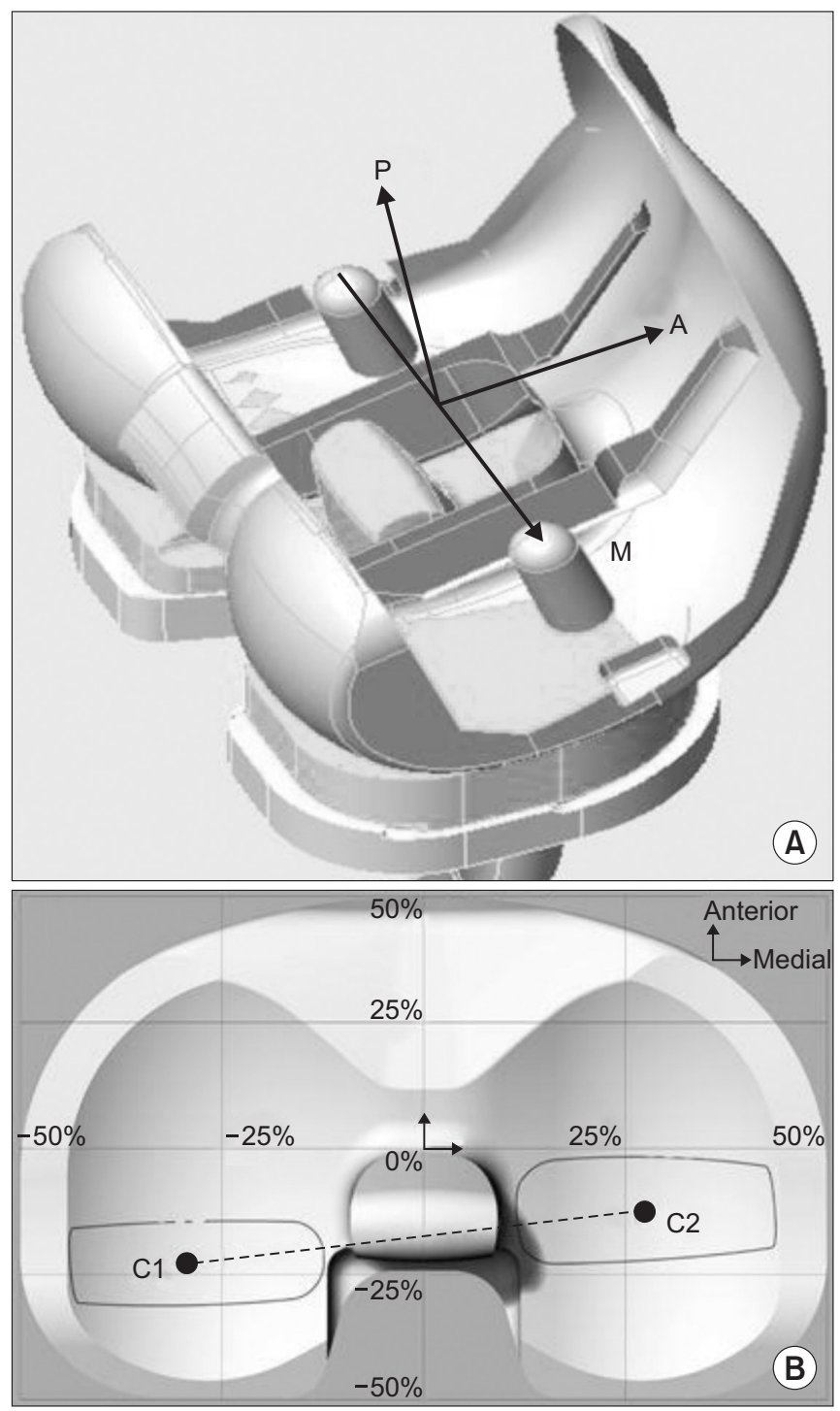

Fig. 1. (A) Coordinate system of the femoral component. (B) Coordinate system of the polyethylene insert. Black circle in each compartment represents outline of contact area between femoral implant and polyethylene insert. A point $(\mathrm{C} 1, \mathrm{C} 2)$ within black line represents the centroid of contact area. A: anterior, M: medial, P: proximal, $\mathrm{C} 1$ : central point 1, C2: central point 2 . of the component was measured using the project of the flexion axis on the tibial plateau surface. The tibial coordinate system was created on the articular surface of the polyethylene insert (Fig. 1B). The origin of the tibial coordinate system was determined as the intersection point of the AP and ML dimensions. The tibiofemoral articular contact area was defined as the intersection between the femoral component and the articulating surface of the polyethylene insert ${ }^{15,17,20)}$. The centroids of the contact areas on the medial and lateral articulating surfaces were used to represent the contact locations on each compartment (Fig. 1B). In cases where the intersection surface was not found, a contact location was defined as the closest point between the femoral component and the articulating surface of the polyethylene insert ${ }^{12,13,19)}$.

\section{Data Analysis}

Since the component sizes are different among the Caucasian and South Korean patients, the translational kinematics data of each subject were normalized by the AP and ML dimensions of the polyethylene tibia insert (Fig. 1B). The data were presented as percentage of the component dimensions. Kinematic differences between the two groups of patients were examined using a Mann-Whitney $U$-test (SPSS ver. 12.0; SPSS Inc., Chicago, IL, USA). Statistically significant differences were indicated when $\mathrm{p}<0.05$.

\section{Results}

\section{Comparison of Femoral Condylar Motions}

The two patient groups showed similar patterns of posterior femoral condyle translations throughout the range of flexion (Figs. 2 and 3). Both medial and lateral condyles translated anteriorly from full extension to $30^{\circ}$ of flexion and then posteriorly with flexion. The femoral condyles of South Korean patients were more anteriorly positioned compared to the Caucasian patients with significant differences at $0^{\circ}, 15^{\circ}$, and maximal flexion ( $p<0.001,0.006$, and 0.001 , respectively). The medial and lateral femoral condyle translations of the two patient groups were similar (Fig. 3). The total excursions of the AP and ML translations of the femoral component were not significantly different between the two groups ( $\mathrm{p}>0.05)$ (Table 2).

The two patient groups also showed similar patterns of internal tibial rotation during the single leg lunge (Fig. 4). The total excursions of the internal tibia rotation were $7.6^{\circ} \pm 1.9^{\circ}$ for the South Korean patients and $8.3^{\circ} \pm 2.5^{\circ}$ for the Caucasian patients ( $p>0.05$ ). 
A

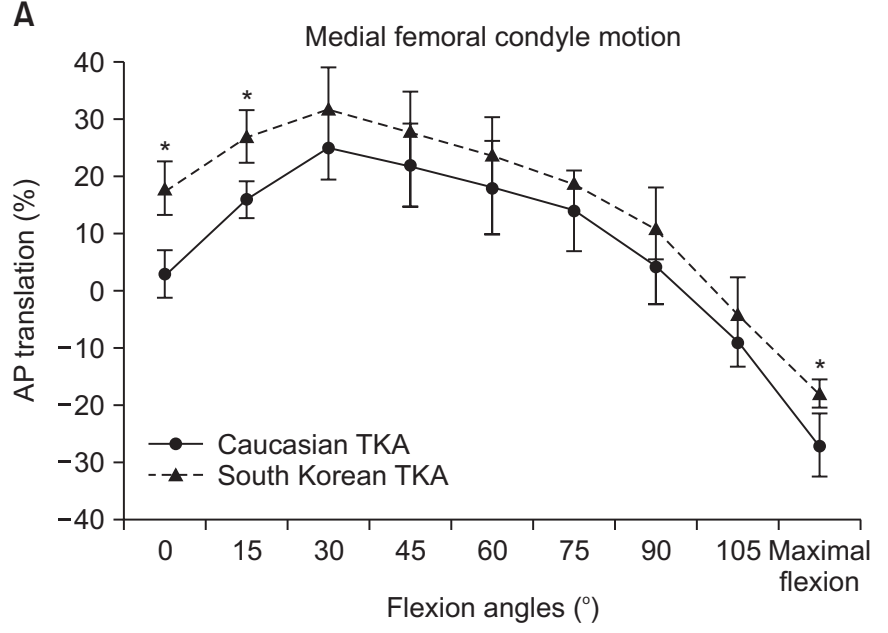

C

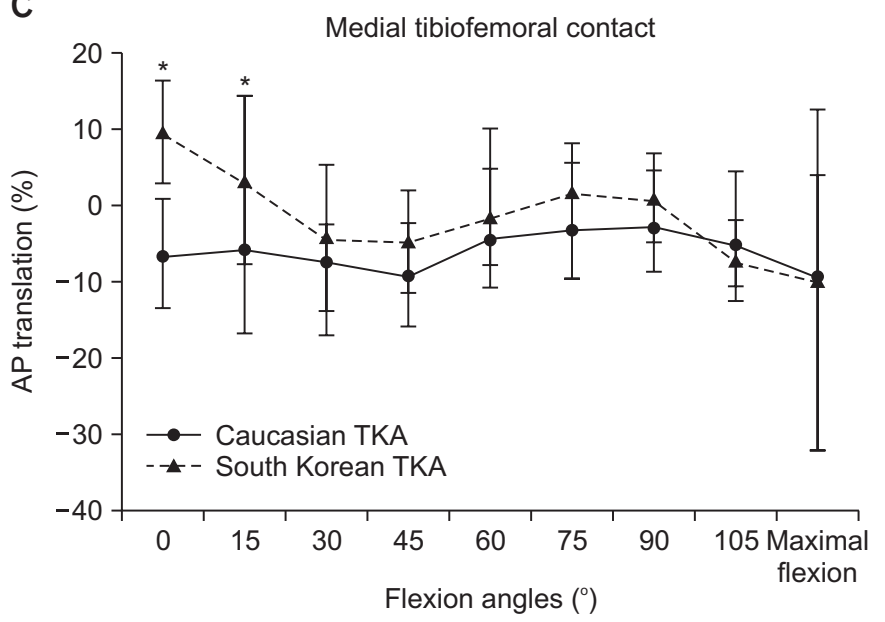

B

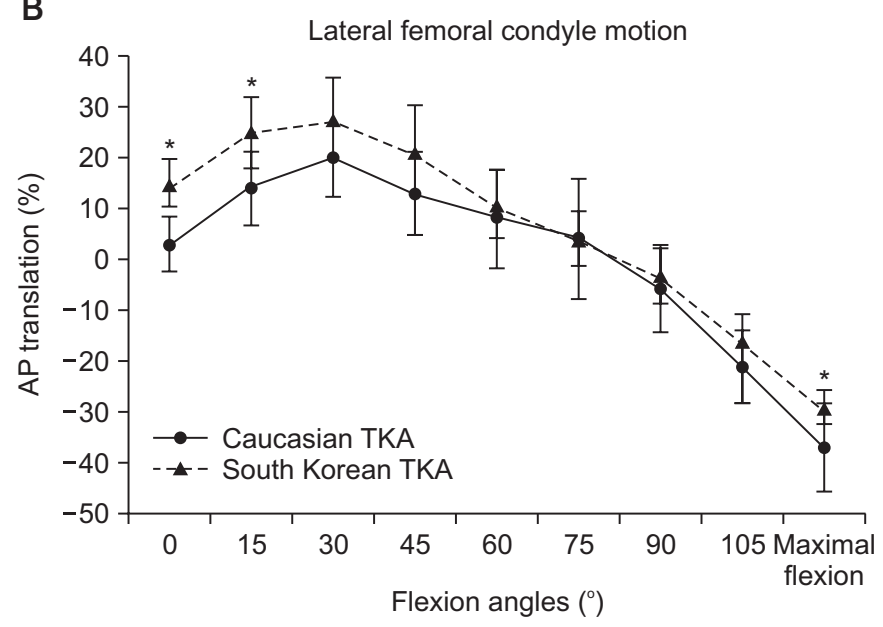

D

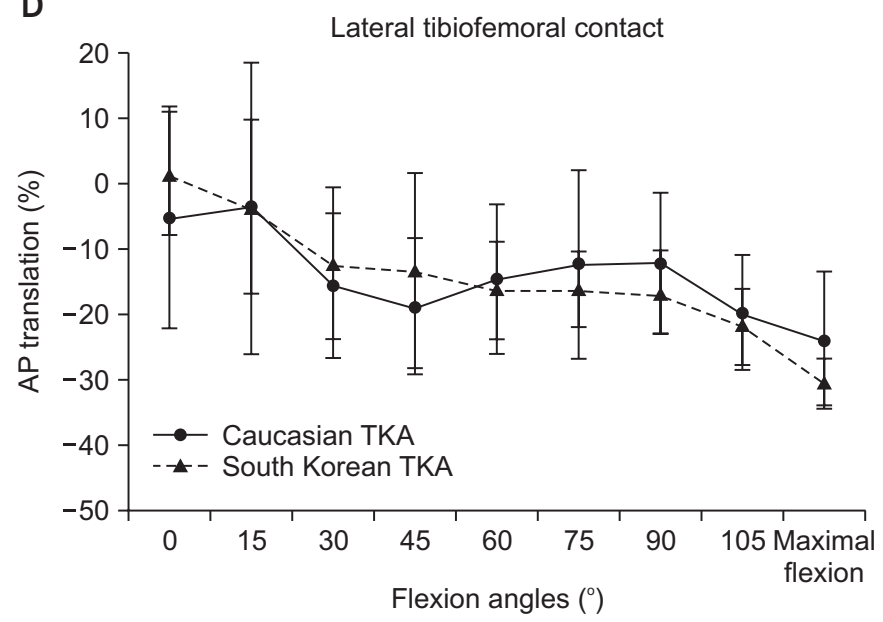

Fig. 2. Contact kinematics of Caucasian and South Korean total knee arthroplasty (TKA) knees in an anteroposterior translation. (A) Normalized medial femoral condylar motions. (B) Normalized lateral femoral condylar motions. (C) Normalized medial tibiofemoral contact kinematics. (D) Normalized lateral tibiofemoral contact kinematics. Positive values mean anterior translation. AP: anteroposterior. ${ }^{*} \mathrm{p}<0.05$.

\section{Comparison of Tibiofemoral Contact Kinematics}

In the medial compartment, the South Korean patients had contact positions more anteriorly at low flexion angles compared to the Caucasian patients ( $\mathrm{p}<0.001$ for $0^{\circ}$ and 0.049 for $15^{\circ}$ ) (Fig. 2). Paradoxical anterior translation of the contact points was observed between $45^{\circ}$ and $90^{\circ}$ of flexion in both patient groups. The total excursion of the medial contact point of South Korean patients was significantly larger than the Caucasian patients (10.0 $\pm 2.8 \mathrm{~mm}$ vs. $7.5 \pm 1.7 \mathrm{~mm}$; $\mathrm{p}=0.021)$.

In the lateral compartment, the ranges of contact point locations in AP direction were not significantly different $(p>0.05)$ (Fig. 2). Paradoxical anterior translation of contact points was observed from $45^{\circ}$ to $90^{\circ}$ of flexion in the Caucasian patients, whereas contact points of the South Korean patients moved posteriorly from full extension to $60^{\circ}$ of flexion and then remained relatively constant until $90^{\circ}$ of flexion. The total excursions of lateral contact points were not significantly different between the South Korean and Caucasian patients $(11.3 \pm 4.2 \mathrm{~mm}$ vs. $11.6 \pm 3.8$ $\mathrm{mm} ; \mathrm{p}>0.05)$. The South Korean patients had contact positions in general more laterally compared to the Caucasian patients in the lateral compartment. Significant differences were observed at $0^{\circ}$ and $90^{\circ}$ of knee flexion between the two groups ( $\mathrm{p}=0.003$ and 0.023, respectively) (Fig. 3). The South Korean patients had larger distance between the medial and lateral contact points compared to the Caucasian patients (Fig. 5).

\section{Discussion}

This study investigated the in vivo knee joint kinematics of a Caucasian patient group and a South Korean patient group after TKA using the same TKA component design during a single leg lunge. We found that the patterns of posterior femoral condyle 
A

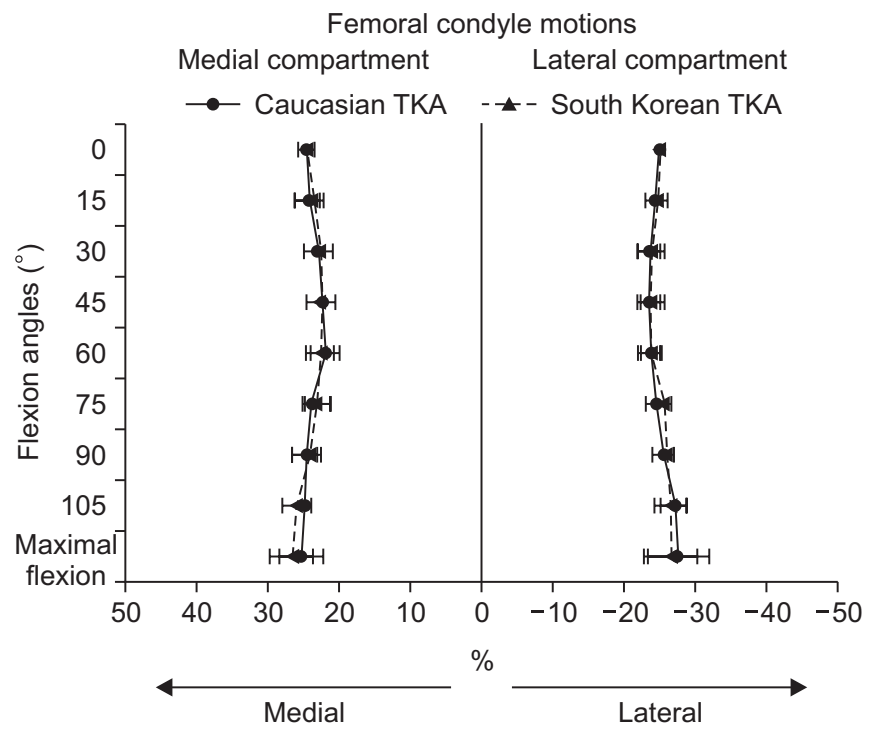

B

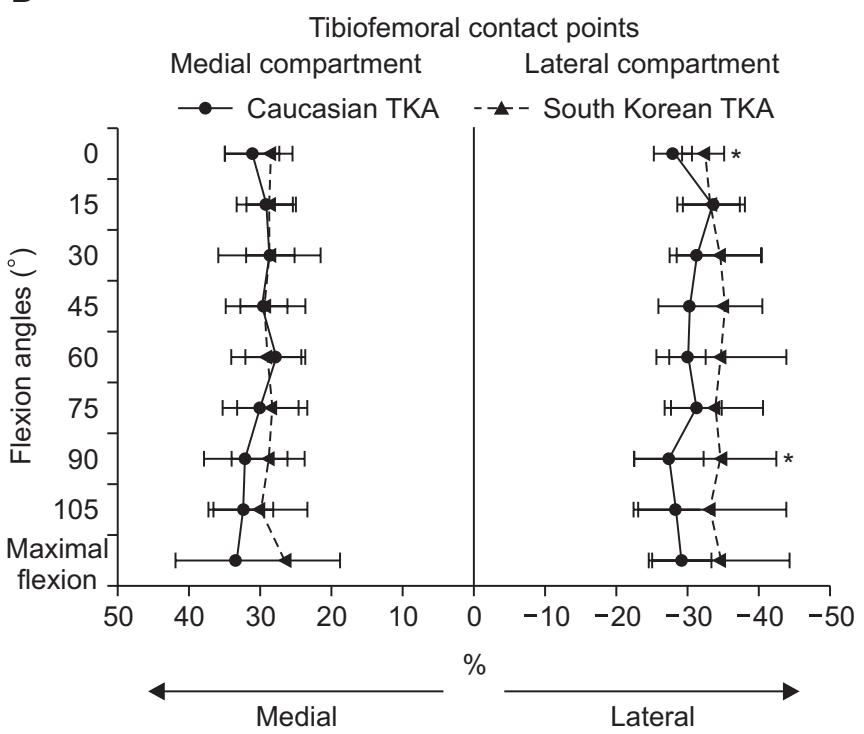

Fig. 3. Contact kinematics of Caucasian and South Korean total knee arthroplasty (TKA) knees in a mediolateral translation. (A) Normalized femoral condylar motions. (B) Normalized tibiofemoral contact kinematics. Positive values mean medial translation. ${ }^{\star} \mathrm{p}<0.05$.

Table 2. Total Excursion of Tibiofemoral Translation and Rotation of Posterior-Substituting Total Knee Arthroplasty Knees

\begin{tabular}{lrrc}
\hline \multicolumn{1}{c}{ Characteristic } & $\begin{array}{c}\text { South } \\
\text { Korean }\end{array}$ & Caucasian & p-value \\
\hline AP translation of femur $(\mathrm{mm})$ & $14.0 \pm 4.7$ & $17.4 \pm 5.5$ & NS \\
ML translation of femur $(\mathrm{mm})$ & $1.6 \pm 1.0$ & $2.0 \pm 1.2$ & NS \\
Internal rotation of tibia $\left(^{\circ}\right)$ & $7.6 \pm 1.9$ & $8.3 \pm 2.5$ & NS \\
\hline
\end{tabular}

Values are presented as mean \pm standard deviation.

AP: anteroposterior, NS: not significant ( $p>0.05)$, ML: mediolateral.

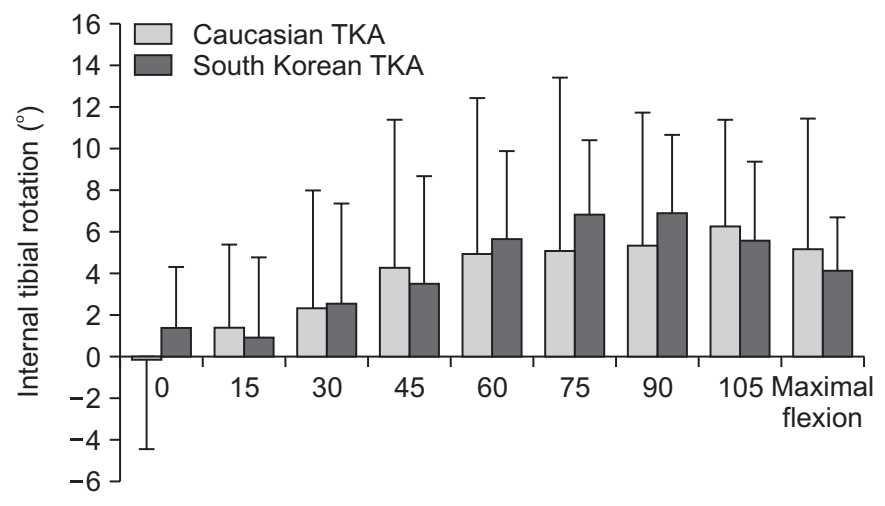

Flexion angles $\left({ }^{\circ}\right)$

Fig. 4. Internal rotation of the tibia in Caucasian and South Korean total knee arthroplasty (TKA) knees. Positive values mean internal rotation.

translations were similar in both patient groups, but the femoral condyles of the South Korean patients were more anteriorly positioned along the flexion path. For tibiofemoral articular contact

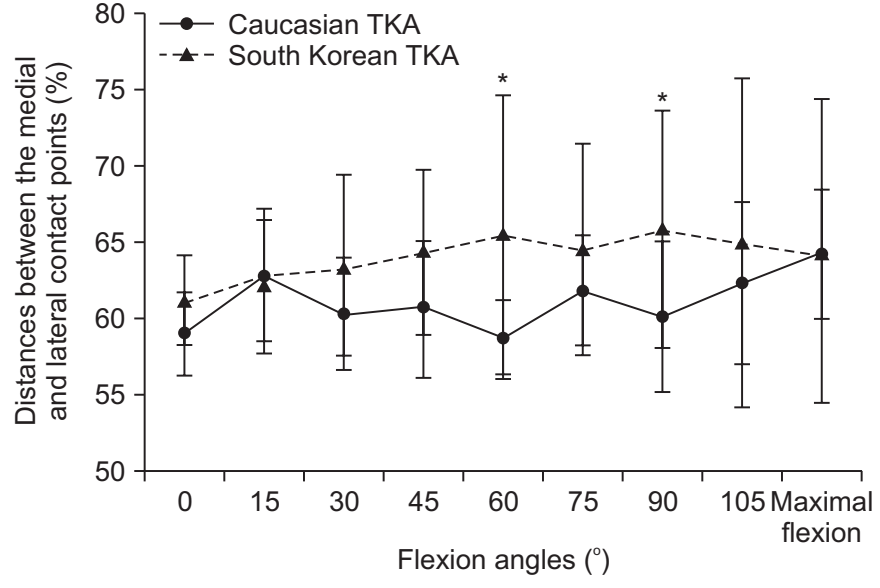

Fig. 5. Normalized contact distances between the medial and lateral contact points in Caucasian and South Korean total knee arthroplasty (TKA) knees. ${ }^{*} \mathrm{p}<0.05$.

kinematics, the South Korean patients had more anterior contact positions on the medial compartment at low flexion angles than the Caucasian patients. In addition, the South Korean patients had more laterally located contact locations on the lateral compartment and larger distances between the medial and lateral contact points. The data indicate that there are distinct ethnic differences in knee kinematics between the Caucasian and South Korean patients after TKA. The data partially proved our hypothesis that the PS-TKA knees of South Korean patients had different contact kinematics compared to those of the Caucasian patients. 
It has been shown that normal knees have constant posterior translation of the distal femur during knee flexion ${ }^{11,18,21}$. However, the paradoxical anterior translation of the distal femur has been observed after PS-TKA knees in the middle range of flexion ${ }^{22-25)}$. Our study also showed the paradoxical anterior translation of contact points from $45^{\circ}$ to $90^{\circ}$ of flexion in both groups after PSTKAs. Considering that the paradoxical anterior translation was shown in both South Korean and Caucasian patients, it is thought that the ethnicity may have little influence on AP translation of the contact points at the mid-range of flexion. As both cruciate ligaments and menisci are excised, AP translation of TKA knees would primarily depend on the shape of the implants if the medial and lateral soft tissue tension could be well balanced. In our study, the conformity of the articular surface of the polyethylene insert might play a major role on the paradoxical anterior translation at the mid-range of flexion. One difference was that the Caucasian patients showed bicondylar anterior translation from $45^{\circ}$ to $90^{\circ}$ of flexion, whereas South Korean patients had paradoxical anterior translation only in the medial compartment. Articular contact points on the lateral compartment of South Korean patients moved posteriorly from extension to $60^{\circ}$ and then remained relatively constant from $60^{\circ}$ to $90^{\circ}$ without showing the mid-range paradoxical translation.

The South Korean patients tended to have more lateral contact points on the lateral compartment compared to the Caucasian patients. In addition, the articular contact centers of the South Korean patients were located more laterally compared to the Caucasian patients. As the same implant design was used for both groups, it is interesting to note that the South Korean patients had smaller knees, but showed larger distances between the contact points in the ML direction compared to the Caucasian patients. While the reason behind is not clearly understood, one assumption could be due to the morphological features of distal femur of Asian knees ${ }^{7,14,26,27)}$. Recent 3D morphologic studies of the distal femur and proximal tibia indicated higher ML/AP ratios for the smaller Asian knees compared to Caucasian knees. This indicated that Asian knees would have wider ML dimensions when compared to the Caucasian knees of the same AP dimensions ${ }^{5}$. The higher ML/AP ratio of distal femur in Asian knees could result in a larger femoral component in Asian patients to ensure coverage of the bony cutting ${ }^{5}$. In our patient group, one or two size larger femoral implants were inserted relative to the tibial implants in the South Korean patients, whereas most Caucasian patients had the same sizes of the femoral and tibial implants. This may suggest that the contact points of the South Korean patients are likely to represent one or two size larger femoral implants when com- pared to the Caucasian patients where the same size polyethylene insert was used among them. Indeed, our data showed that the South Korean patients tended to have more lateral contact points on the lateral compartment. As the ML/AP ratios of current TKA implants were developed based on Caucasian knees, ethnic differences on ML/AP ratio of the distal femur should be considered in future improvement of TKA implants for Asian patients.

South Korean patients experienced more anterior contact positions at the medial compartment at low flexion angles. Even though the mechanisms causing this is unclear, previous studies have reported similar findings. Leszko et al. ${ }^{11)}$ compared normal knee kinematics between healthy Caucasian and Japanese populations and they observed more anterior contact of medial femoral condyle for healthy Japanese women than healthy Caucasian men ${ }^{11}$. Liu et al. ${ }^{28)}$ also reported relatively anterior contact positions at the medial compartment in 11 Japanese patients operated using the same component design of our patients. Although the clinical relevance is not clear yet, different contact kinematics at low flexion angles may lead to different tibiofemoral loading inside the knee. Caucasian patients had a medial pivot pattern during the single leg, weight bearing lunge, while South Korean patients showed bicondylar posterior translation of contact points. Interestingly, we found that contact points at maximum flexion were more posterior in the Caucasian patients. This phenomenon could probably be due to more anterior contact positions in South Korean patients initially.

There are several limitations of this study that should be pointed out. Despite the same implant design was used for both patient groups, Caucasian patients, in general, had larger TKA implants compared to the South Korean patients. Therefore, we normalized the motion data using the polyethylene insert dimensions to minimize the joint size effect on knee kinematics measurements. As knee motion is also influenced by soft tissue conditions, soft tissue balance after TKA affects the kinematics results. There was no quantitative information on the preoperative soft tissue contracture and no information on the amount of soft tissue release during TKA procedures in both patient groups due to the retrospective nature of the experimental design. However, all knees were recruited using the criterion of clinically well balanced during operation. Our results should be limited to a single TKA design and a single leg lunge. Different TKA implant designs or different testing activities could affect the in vivo contact kinematics of the TKAs ${ }^{29,30}$. As patients were included in two different countries, it was difficult to match the preoperative characteristics of patients (ROM, proportion of gender, and degree of contracture). However, the surgical techniques were 
similar (acceptable ligament balance, implant sizing, and implant alignment and rotation) since the operating surgeon in Korea of this study was trained at Massachusetts General Hospital. Finally, our sample size is relatively small due to funding limitation and difficulties in coordinating tests in two countries. Future studies should recruit a larger sample size.

\section{Conclusions}

The present study demonstrated that South Korean TKA patients had more anterior contact points on the medial compartment, more lateral contact points on the lateral compartment and bicondylar femoral posterior translation rather than medial pivot pattern compared to the Caucasian TKA patients. Different tibiofemoral articular contact kinematics should be considered for the design of bearing articular surface in Asian patients.

\section{Conflict of Interest}

No potential conflict of interest relevant to this article was reported.

\section{References}

1. Koh IJ, Kim TK, Chang CB, Cho HJ, In Y. Trends in use of total knee arthroplasty in Korea from 2001 to 2010. Clin Orthop Relat Res. 2013;471:1441-50.

2. Akiyama H, Hoshino A, Iida H, Shindo H, Takakura Y, Miura H, Yamamoto K, Yoshiya S, Hasegawa Y, Shimamura T, Kurosaka M, Otsuka H, Kawanabe K, Kawate K, Harada Y, Nakamura T; Implant Committee, Japanese Orthopaedic Association: a pilot project for the Japan arthroplasty register. J Orthop Sci. 2012;17:358-69.

3. Kim TK. Special considerations for TKA in Asian patients: editorial comment. Clin Orthop Relat Res. 2013;471:143940.

4. Iorio R, Kobayashi S, Healy WL, Cruz AI Jr, Ayers ME. Primary posterior cruciate-retaining total knee arthroplasty: a comparison of American and Japanese cohorts. J Surg Orthop Adv. 2007;16:164-70.

5. Mahfouz M, Abdel Fatah EE, Bowers LS, Scuderi G. Threedimensional morphology of the knee reveals ethnic differences. Clin Orthop Relat Res. 2012;470:172-85.

6. Urabe K, Mahoney OM, Mabuchi K, Itoman M. Morphologic differences of the distal femur between Caucasian and Japanese women. J Orthop Surg (Hong Kong). 2008;16:312-5.
7. Yue B, Varadarajan KM, Ai S, Tang T, Rubash HE, Li G. Differences of knee anthropometry between Chinese and white men and women. J Arthroplasty. 2011;26:124-30.

8. Hovinga KR, Lerner AL. Anatomic variations between Japanese and Caucasian populations in the healthy young adult knee joint. J Orthop Res. 2009;27:1191-6.

9. Harvey WF, Niu J, Zhang Y, McCree PI, Felson DT, Nevitt M, Xu L, Aliabadi P, Hunter DJ. Knee alignment differences between Chinese and Caucasian subjects without osteoarthritis. Ann Rheum Dis. 2008;67:1524-8.

10. Tamari K, Tinley P, Briffa K, Aoyagi K. Ethnic-, gender-, and age-related differences in femorotibial angle, femoral antetorsion, and tibiofibular torsion: cross-sectional study among healthy Japanese and Australian Caucasians. Clin Anat. 2006;19:59-67.

11. Leszko F, Hovinga KR, Lerner AL, Komistek RD, Mahfouz MR. In vivo normal knee kinematics: is ethnicity or gender an influencing factor? Clin Orthop Relat Res. 2011;469:95106.

12. Hanson GR, Suggs JF, Freiberg AA, Durbhakula S, Li G. Investigation of in vivo 6DOF total knee arthoplasty kinematics using a dual orthogonal fluoroscopic system. J Orthop Res. 2006;24:974-81.

13. Bingham J, Li G. An optimized image matching method for determining in-vivo TKA kinematics with a dual-orthogonal fluoroscopic imaging system. J Biomech Eng. 2006;128:58895.

14. Li P, Tsai TY, Li JS, Zhang Y, Kwon YM, Rubash HE, Li G. Morphological measurement of the knee: race and sex effects. Acta Orthop Belg. 2014;80:260-8.

15. Suggs JF, Hanson GR, Park SE, Moynihan AL, Li G. Patient function after a posterior stabilizing total knee arthroplasty: cam-post engagement and knee kinematics. Knee Surg Sports Traumatol Arthrosc. 2008;16:290-6.

16. Hanson GR, Suggs JF, Kwon YM, Freiberg AA, Li G. In vivo anterior tibial post contact after posterior stabilizing total knee arthroplasty. J Orthop Res. 2007;25:1447-53.

17. Hanson GR, Park SE, Suggs JF, Moynihan AL, Nha KW, Freiberg AA, Li G. In vivo kneeling biomechanics after posterior stabilized total knee arthroplasty. J Orthop Sci. 2007; 12:476-83.

18. Qi W, Hosseini A, Tsai TY, Li JS, Rubash HE, Li G. In vivo kinematics of the knee during weight bearing high flexion. J Biomech. 2013;46:1576-82.

19. Li G, Wuerz TH, DeFrate LE. Feasibility of using orthogonal fluoroscopic images to measure in vivo joint kinematics. J 
Biomech Eng. 2004;126:314-8.

20. Moynihan AL, Varadarajan KM, Hanson GR, Park SE, Nha KW, Suggs JF, Johnson T, Li G. In vivo knee kinematics during high flexion after a posterior-substituting total knee arthroplasty. Int Orthop. 2010;34:497-503.

21. Kozanek M, Hosseini A, Liu F, Van de Velde SK, Gill TJ, Rubash HE, Li G. Tibiofemoral kinematics and condylar motion during the stance phase of gait. J Biomech. 2009;42: 1877-84.

22. Fantozzi S, Catani F, Ensini A, Leardini A, Giannini S. Femoral rollback of cruciate-retaining and posterior-stabilized total knee replacements: in vivo fluoroscopic analysis during activities of daily living. J Orthop Res. 2006;24:2222-9.

23. Dennis DA, Komistek RD, Mahfouz MR, Haas BD, Stiehl JB. Multicenter determination of in vivo kinematics after total knee arthroplasty. Clin Orthop Relat Res. 2003;(416):37-57.

24. Sharma A, Komistek RD, Scuderi GR, Cates HE Jr. Highflexion TKA designs: what are their in vivo contact mechanics? Clin Orthop Relat Res. 2007;464:117-26.

25. Tamaki M, Tomita T, Watanabe T, Yamazaki T, Yoshikawa
H, Sugamoto K. In vivo kinematic analysis of a high-flexion, posterior-stabilized, mobile-bearing knee prosthesis in deep knee bending motion. J Arthroplasty. 2009;24:972-8.

26. Li P, Tsai TY, Li JS, Wang S, Zhang Y, Kwon YM, Rubash HE, Li G. Gender analysis of the anterior femoral condyle geometry of the knee. Knee. 2014;21:529-33.

27. Yue B, Varadarajan KM, Ai S, Tang T, Rubash HE, Li G. Gender differences in the knees of Chinese population. Knee Surg Sports Traumatol Arthrosc. 2011;19:80-8.

28. Liu F, Ohdera T, Miyamoto H, Wasielewski RC, Komistek $\mathrm{RD}$, Mahfouz MR. In vivo kinematic determination of total knee arthroplasty from squatting to standing. Knee. 2009;16: 116-20.

29. Banks SA, Hodge WA. Implant design affects knee arthroplasty kinematics during stair-stepping. Clin Orthop Relat Res. 2004;(426):187-93.

30. Banks SA, Hodge WA. 2003 Hap Paul Award Paper of the International Society for Technology in Arthroplasty. Design and activity dependence of kinematics in fixed and mobilebearing knee arthroplasties. J Arthroplasty. 2004;19:809-16. 